\title{
Hacia una articulación entre la teoría marxista del valor y la teoría de la acción comunicativa de Jürgen Habermas
}

\author{
Towards an Articulation between the Marxist \\ Theory of Value and the Theory of Communicative \\ Action by Jürgen Habermas
}

Juan Alberto Fraiman*

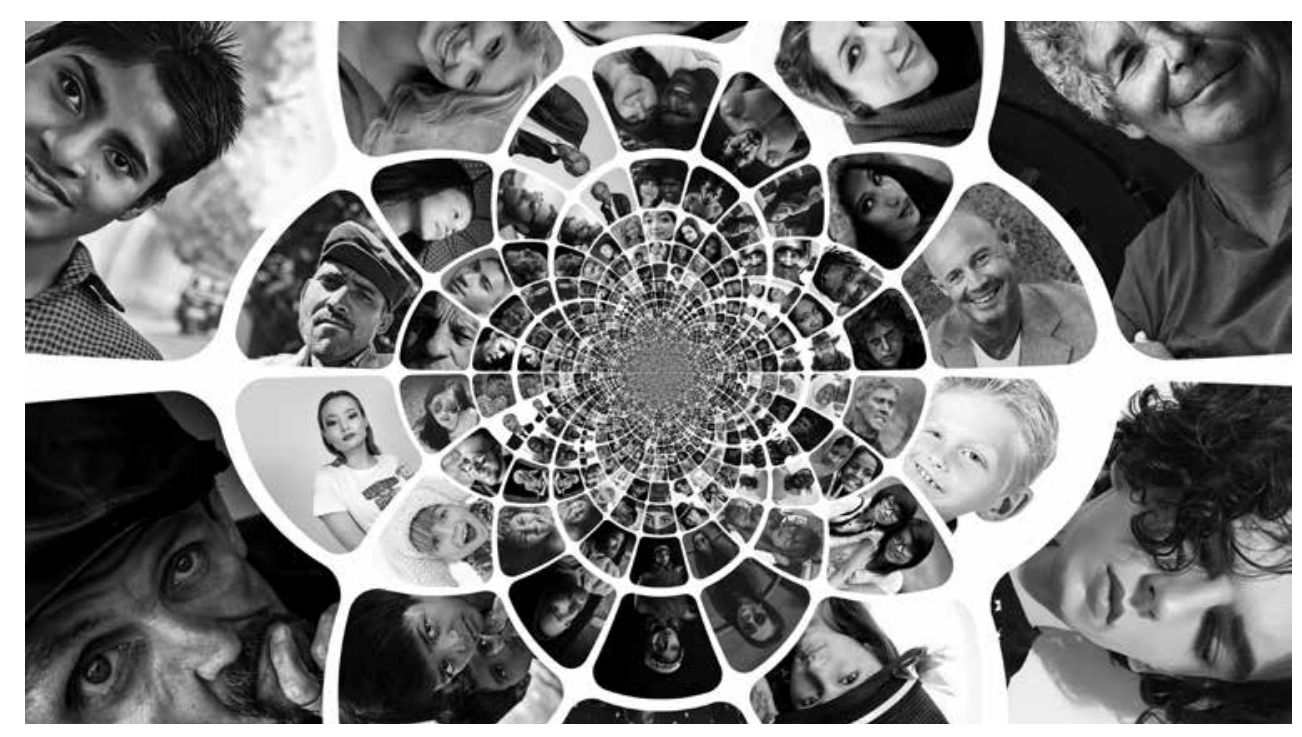

\section{Resumen}

El propósito del presente artículo es destacar la relevancia que ocupa la perspectiva marxista del valor-trabajo en la teoría de la acción comunicativa de Jürgen Habermas. De esa manera, se trata de desmentir o relativizar la frecuente interpretación que juzga el enfoque de Habermas como ajeno, e incluso contario, al marxismo. Ello no significa que las dos teorías simplemente se acoplen en perfecta armonía. No es difícil hallar críticas al pensamiento de Marx en algunas líneas habermasianas. $\mathrm{Al}$ mismo tiempo, se reconoce que, desde una postura marxista, es posible señalar

Citar este artículo como: Fraiman, J. A. (2020). Hacia una articulación entre la teoría marxista del valor y la teoría de la acción comunicativa de Jürgen Habermas. Revista Papeles, 11(22), 43-58.

Fecha de recibido: octubre 10 de 2019 - Fecha de aceptación: noviembre 15 de 2019

* Doctor en Ciencias Sociales (Universidad Nacional de Entre Ríos, Argentina). Profesor Adjunto Ordinario de Epistemología en la Universidad Nacional de Entre Ríos (UNER) y en la Universidad Autónoma de Entre Ríos (UADER). Correo electrónico: juanfraiman@hotmail.com 
importantes límites y problemas a la propuesta habermasiana. En definitiva, nuestro escrito intenta justificar la necesidad de profundizar en una articulación entre ambas producciones teóricas con la finalidad de enriquecer el análisis sobre el mundo social desde una orientación crítica.

Palabras clave: teoría valor-trabajo, acción comunicativa, mundo de la vida, marxismo.

\begin{abstract}
The purpose of this article is to highlight the relevance of the Marxist perspective of value-work in the Theory of Communicative Action by J. Habermas. In this way, it is a question of debunking or relativizing the frequent interpretation that judges Habermas's approach to be alien and even contrary to Marxism. This does not mean that the two theories simply are coupled in perfect harmony. It is not difficult to find criticism of Marx's thinking in some Habermasian lines. At the same time, it is recognized that, from a Marxist stance, it is possible to point important limits and problems to the Habermasian proposal. In short, our writing tries to justify the need to deepen an articulation between the two theoretical productions in order to enrich the analysis of the social world from a critical orientation.
\end{abstract}

Keywords: labor theory of value, communicative action, lifeworld, Marxism.

\title{
Presentación
}

La teoría de la acción comunicativa ${ }^{1}$ de Jürgen Habermas ha constituido sin dudas un hito importante en la teoría social contemporánea, transformándose rápidamente en objeto de amplios debates, críticas y disputas (Guiddens et al., 1991). Uno de los aspectos más álgidos de discusión es su vinculación con el marxismo. En términos globales, no resulta para nada transparente su pertenencia a la tradición marxista, aun heterodoxa (Sitton, 2006). Incluso podemos encontrar algunos pasajes en donde el propio Habermas deja entrever -o lo pone manifiestamente en claro- cierto abandono del marxismo ${ }^{2}$.

1 De ahora en más denominaremos TAC a la teoría de la acción comunicativa de Habermas.

2 Por ejemplo, Habermas habla del agotamiento de las utopías derivadas del mundo del trabajo (1988); también lo hace cuando refiere al "envejecimiento del paradigma de la producción" (1989b, pp. 99-107).
Más allá de las consideraciones que el mismo autor pueda hacer sobre su obra, el propósito de este escrito es pensar una posible relación entre la teoría de la acción comunicativa con la teoría del valor-trabajo en Marx. Pero, ¿cuál sería la finalidad y el provecho de tal tarea?

Para comenzar a justificar semejante misión, hacernos algunas consideraciones generales acerca de la perspectiva de Habermas en orden de plantear su posible contacto con Marx como algo, por el momento, problemático.

En primer lugar, diremos que la TAC significó el intento de articular sistemáticamente las contribuciones de una teoría global de la sociedad con una tipología de la acción social. De esa manera, se busca aportar explicaciones que vayan más allá de la actividad intencional de los individuos y, a la vez, se haga justicia a la acción subjetiva como elemento fundamental de la dinámica social. En ese sentido, 
la construcción teórica de Habermas se puede comprender en continuidad con el programa de Talcoltt Parson, en tanto su obra se lea como un continuo intento de integración de ambos paradigmas (Habermas, 1987, pp. 281-284).

Asimismo, Habermas subraya la necesidad de exponer la problemática de la explicación de los procesos de modernización sin identificarlos sin más con los procesos de reificación. De esta reducción no está libre, según Habermas, toda la anterior teoría crítica que abreva en las figuras de Karl Marx y Max Weber. En especial, al establecer o admitir implícitamente que la actividad racional con arreglo a fines es el modelo de acción social; allí se inscribe también una concepción de la racionalidad restringida en un sentido instrumental y funcional. En términos de una gnoseología más amplia, se trata de la persistencia implícita del modelo sujeto-objeto en el marco de una filosofía de la conciencia y de una racionalidad centrada en la subjetividad que supone, como situación originaria, un individuo solitario, enfrentado a un estado de cosas específico, proponiendo fines y eligiendo los medios más adecuados en determinadas condiciones dadas, bajo un sistema de preferencias y valores ya vigentes (Habermas, 1989b). Con esos presupuestos se da una rígida alternativa entre, por un lado, una racionalidad pensada como dominio y control (de sí mismo y de todo aquello que se pueda objetivar) más una conciencia o pensamiento que conceptualiza subsumiendo lo múltiple en la unidad y, como contrapartida, tendría lugar la espontaneidad - acaso "muda" o no lingüística - creativa y reconciliada simbióticamente en una totalidad dialéctica reconfigurada que, de manera consecuente no puede reconocerse como racional (Habermas, 1987, pp. 7-8).

En ese orden, el enfoque comunicativo habermasiano propone pensar las relaciones intersubjetivas como la base que constituye a las subjetividades en los procesos de individualización y conformación de las identidades personales, pero también en el ordenamiento social normativo y en las distintas formas institucionales que constituyen las esferas simbólicas del mundo de la vida (Habermas, 1987 y 1990). De modo que los procesos cosificadores se piensan en términos de intersubjetividad o comunicación dañada de manera sistemática, ocasionando efectos en la esfera individual y en los patrones sociales de reproducción simbólica. Pero el eje se desplaza ahora del sujeto aislado o desde las condiciones presuntamente "preinteractivas", a los mecanismos o patrones de interacción que hacen posible la vida social y constituyen al individuo (Habermas, 1989b).

En términos generales, siguiendo a Habermas, la acción comunicativa se comprende bajo el trasfondo de un mundo de la vida ya dado, siempre envolvente y suministrador de los recursos simbólicos que estructuran, hacen posible y reproducen el sentido compartido y el mundo simbólico en general. Como veremos después, a partir del entendimiento mutuo, ligado a la acción comunicativa propiamente dicha, logran desarrollarse $y$ autonomizarse - del mundo de la vida - otro tipo de mecanismos de vinculación no simbólicos. Ello es posible a través de los medios de control o regulación sistémica que van a operar coactivamente sobre los medios de reproducción simbólicos, dañando o distorsionando el entendimiento mutuo de base. Se desenvuelven entonces procesos de integración social - ligados al mundo de la vida- y procesos de integración sistémica que tienden a expandirse y sobrepujar a los anteriores (Habermas, 1987, pp. 169 y ss.).

Aunque Habermas señala que su concepción comunicativa de la vida social no puede agotar la explicación de los fenómenos sociales en su totalidad y, particularmente, de los procesos de reificación, su manera de plantear la conflictividad subyacente entre mecanismos sistémicos y sociales de integración parece desdibujar la anatomía marxista de una teoría social. Esto es, en tal versión de 


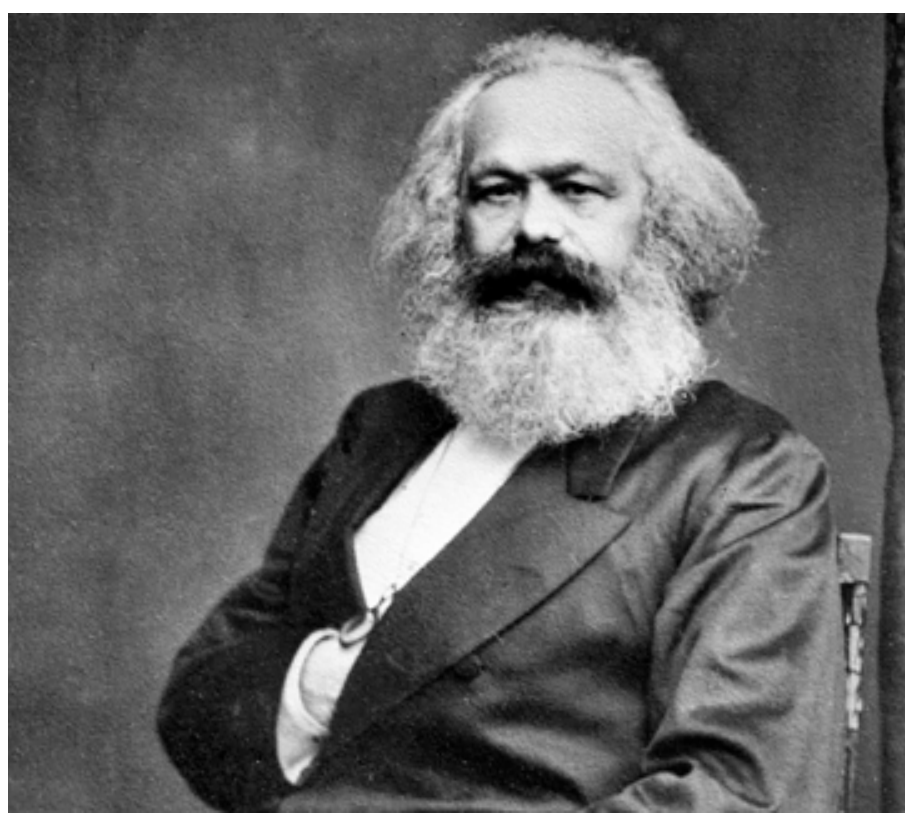

Karl Marx

la vida social aparenta diluirse la concepción materialista y la incidencia de la estructura productiva para explicar el conflicto social, la desigualdad, los problemas en la distribución de la riqueza, los procesos de alienación derivados de las relaciones en torno al trabajo y la propia explotación laboral.

Sin embargo, vamos a sostener aquí que el planteo central de la TAC no nos obliga forzosamente a comprenderla como una teoría 'no-marxista', que intenta desplazar a Marx, renunciando, por lo tanto, a su intención teórico-práctica de denunciar los dolores del sistema social capitalista vigente y a ofrecer un diagnóstico orientador de la praxis emancipadora. Por el contrario, afirmaremos que resultaría de gran fecundidad analítica trazar las importantes relaciones que ligan la TAC con la teoría del trabajo-valor de Marx. Claro que eso no quiere decir simplemente que la TAC sea la aplicación teórica de la teoría marxista del valor-trabajo, en nuevas condiciones sociohistóricas. Sin dudas, surgirán obstáculos, limitaciones, revisiones, otros cruces y problematizaciones de sumo interés teórico para las ciencias sociales contemporáneas.
¿Cuál es nuestra propuesta? Una articulación entre la TAC de Jürgen Habermas y la teoría del trabajo-valor de Karl Marx, advirtiendo entonces que tal ensambladura no puede significar la mera adición de dos producciones teóricas o la forzada armonización entre ambos autores. En lugar de ello, debería constituir una puesta en relación que implique el hallazgo de puntos en común, prosiguiendo $y$ ahondando en algunas posibles interpretaciones que el mismo Habermas ya ha echado a andar y, al mismo tiempo, plantear en qué sentido la comparación recíproca puede poner en evidencia algunos problemas y límites de un lado y del otro.

Con esto tampoco insinuamos que ambos autores se encuentran, por así decirlo, a la misma altura ni sean equiparables. Naturalmente, se trata, en el caso de Marx, de un inobjetable clásico de la teoría social y de la crítica a la economía política, en tanto que Habermas aparece como un importante pensador contemporáneo, aunque claro deudor de aquellos grandes autores, entre los cuales se cuenta al destacado escritor de Tréveris. Consideramos, no obstante, que ello no constituye un impedimento para efectuar un ir y venir entre Marx y Habermas que pueda resultar enriquecedor para justipreciar, por caso, los alcances de la crítica en la TAC, hacer una relectura no dogmática y revitalizante de la teoría del valor y no conjeturar apresuradamente una presunta disyuntiva insalvable entre ambos senderos teóricos.

Pues bien, ese marco general apenas trazado anteriormente pertenecería a un programa de largo aliento. En el presente artículo pretendemos ensayar un esbozo de esa articulación que tenga como objetivo mostrar por qué valdría la pena llevarla a cabo, o en qué sentido podría llegar a resultar provechosa tal articulación.

En consecuencia, aquí nos ocuparemos centralmente en señalar la apropiación y continuidad que el propio Habermas ya va indicando, con respecto al marxismo. En ese 
sentido, aparece la referencia explícita de presentar la teoría marxista del trabajo-valor como caso de colonización interna del mundo de la vida. Ello nos conducirá a resaltar el carácter dual del trabajo y de la mercancía que en la TAC no solo no se abandona sino que más bien se enfatiza, al punto de constituirse en un eje imprescindible proveedor de un sentido fundamental a todo el planteo habermasiano. Luego, repasaremos los límites y deficiencia que, a juicio de Habermas, no pueden pasarse por alto en la teoría del valor, pero lo pondremos en vinculación con algunas objeciones dirigidas hacia la TAC. Ello nos permitirá estimar algunas diferencias significativas y algunos problemas importantes en una perspectiva y en la otra. Por último, haremos una reflexión en torno a, por un lado, las ventajas que significan la articulación entre una teoría comunicativa y del valor sin desconocer los problemas que todavía hoy permanecen en una versión comunicativa de la sociedad frente a la teoría del valor y, a la inversa, los problemas que persisten en una teoría del valor.

\section{La introducción del marxismo en la teoría de la acción comunicativa de Habermas}

El mismo subtítulo puede desconcertar, como decíamos al comienzo del presente escrito, en tanto que suele ubicarse a Habermas distanciado del marxismo, en particular, tras la elaboración y publicación de su Teoría de la acción comunicativa.

Cabe la aclaración: el desarrollo que vamos a exponer aquí no se propone establecer el grado de pertenencia y fidelidad de la TAC a Marx; menos aún determinar si Habermas es o no marxista. Sin embargo, vamos a intentar mostrar que al menos la crítica a la economía política expuesta principalmente en El Capital de Marx y, en particular su teoría del valor ligada al trabajo, no ocupa un rol menor en la TAC. A tal punto que pasar por alto ello conduce a malentendidos fundamentales en la comprensión de la TAC. Todo esto pese a que, en términos cuantitativos, la referencia a Marx es muy escasa en relación al lugar que ocupan otros autores y corrientes - como Weber, Parsons, Alfred Schütz, Durkheim o Mead- en los dos tomos que componen la obra principal en que Habermas (1987b) desarrolla con mayor sistematicidad su teoría. En los demás textos complementarios la cita a Marx es también escasa (Habermas, 1989a). Peor aún, entre las pocas alusiones sueltas que realiza sobre Marx, daría la impresión de que su figura parece superada y que su teoría de la comunicación supone una exagerada idealización del lenguaje que desconoce las condiciones materiales.

No obstante, comenzaré abordando este asunto con una pregunta muy precisa: ¿bajo qué circunstancias aparece citado Marx en el desarrollo de la Teoría de la acción comunicativa?

Pues bien, las menciones más extensas y desarrolladas sobre Marx aparecen en las 'Consideraciones finales' del segundo tomo de la TAC (1987, pp. 427 y ss.) —otra razón más para pensar en el carácter aparentemente marginal del marxismo en tal obra.

En concreto, tras un tratamiento extenso de la perspectiva de Parsons, Habermas retorna a Max Weber - del que se había ocupado anteriormente. todavía de manera más espaciosa - para tratar lo que denomina las 'paradojas' en los procesos de racionalización social que destruyen viejas formas de coacción, pero determina nuevos padecimientos en torno a la pérdidas de la libertad y el sentido de orientación en el marco de la vida moderna (1987, p. 428). Luego del tránsito por Parsons, se concluye que tal problemática o paradoja de la racionalización debe ser considerada a la luz de una concepción de la sociedad 
moderna diferenciada en su integración social y sistémica, con la consecuente necesidad de establecer una cuidadosa delimitación metodológica y analítica de ambas modalidades. Ello sería una conclusión derivada de su estudio de Parsons que serviría para calibrar mejor el problema emergente en la lectura de Max Weber.

Cabe destacar que su apropiación de Weber no está exenta de críticas y de intención correctiva; gran parte de las ricas y profundas indagaciones weberianas y la vigencia de su diagnóstico no deben eclipsar, a juicio de Habermas, algunas inconsistencias y estrechamientos en cuanto a su teoría de la acción social y de los procesos de racionalización como modernización capitalista (1987b, p. 430). En definitiva, estas interpretaciones hacen al cotejo con su teoría de la acción comunicativa en sentido restringido (es decir, la tipología de la acción social que propone el propio Haber$\operatorname{mas}^{3}$ ) y de racionalidad comunicativa que haría justicia a la separación analítica entre formas de racionalización social diferentes en el mundo moderno.

Ahora bien, es en este preciso punto en que Habermas apela a Weber para dar cuenta de las paradojas de la modernización; dice hacerlo desde el espíritu propio del marxismo occidental (de Lukács en adelante, pasando

3 En el tomo I de la TAC, subtitulado Racionalización de la acción y racionalización social, Habermas discute la teoría de la racionalización de Max Weber y propone una tipología de la acción social alternativa cuyo centro estaría dado por la acción comunicativa ligada al entendimiento mutuo y no en la acción racional con arreglo a fines, según la perspectiva que no solo sostuvo Weber sino que también constituyó una herencia teórica muy fuerte en la tradición del marxismo occidental -de Lukács a Adorno-y derivó muchas veces en la identificación directa entre racionalización y cosificación (1987a, pp. 197 y ss.) especialmente por la primera generación de la Escuela de Fráncfort). Bajo esas premisas, se trata de postular el modo de producción específicamente capitalista como "mecanismo impulsor" de la expansión de los procesos de la burocratización de la administración estatal y amplificación de la racionalidad instrumental a todos los órdenes de la vida (1987b, pp. 465-466).

Esto es, los efectos patológicos y cosificadores no se pueden simplemente señalar como inscriptas en las transformaciones culturales y sociales de la modernidad - a saber, los procesos de secularización de las imágenes del mundo, la pérdida de su capacidad de integración social, articulados en un desencantamiento de la naturaleza y una expansión ilimitada de la dominación legal—, sino que debe suministrarse de manera más selectiva un anclaje en las condiciones materiales de producción. En ello reside la importancia de destacar y no perder de vista el factor de la lucha de clases o la dinámica suministrada por el modo de producción capitalista como componente fundamental (1987b, 468). Entonces, las deformaciones o daños infligidos no se pueden entender, grosso modo, como acontecimientos ínsitos a los procesos de racionalización de la vida social. No solo porque habría que discernir mejor diferentes modos de racionalización, patrones de integración social, procesos de aprendizajes y diferenciaciones internas, etc., sino porque tales procesos de transformación a nivel cultural y social deben ser concebidos a la par de la problemática específica que acontece en la producción económica capitalista. Bajo esos términos, Habermas admite que es necesario apelar a Marx (1987b, pp. 465-466).

Pero ello no quiere decir atribuir todos los efectos sociales patológicos a las condiciones económicas porque, por ejemplo, es fácil notar que las consecuencias de la expansión burocrática afecta por igual la vida proletaria y burguesa. De esa manera, Habermas rescata del marxismo occidental, una postura materialista 
pero no mecanicista: no se trata de reducir los problemas simbólicos, jurídicos, psicológicos, políticos, culturales o de conciencia -en pocas palabras, a nivel de la superestructuraa un determinismo economicista. De ahí la denominación de 'mecanismo impulsor', pues quiere dar a entender algo así como un 'motor' que pone en marcha un proceso pero no lo determina directamente ni se pueden derivar de él, de manera inmediata, todos los daños que suceden en la vida social.

Con todo, Habermas también se aparta de esta herencia marxista occidental en dos aspectos fundamentales. En primer lugar, toma distancia de una lectura hegelianizante que realiza el joven Lukács, al concebir el pasaje de la cosificación a la emancipación como un necesario devenir dialéctico que transcurre puntualmente en la conciencia del proletariado. En segundo término, Habermas está en desacuerdo con una interpretación de la racionalidad social exclusivamente como instrumental. Tal intelección habilitaría un entendimiento del dominio social, en condiciones modernas, como un proceso totalizador que ya ni siquiera podría ser contrarrestado con una conciencia proletaria revolucionaria -a la manera del joven Luckács-, sino, en todo caso, con algún tipo de determinación espontánea de carácter forzosamente irracional. Esta última visión cree Habermas verla en la primera generación de los pensadores de Frankfurt, especialmente en los textos tardíos de Adorno y Horkheimer (1987b, pp. 6-7; pp. 470-471).

En cambio, una concepción de la sociedad en dos planos, como mundo de la vida y como sistema permitiría, a juicio de Habermas, pensar dos formas de racionalización substancialmente diferentes que contribuiría a efectuar una apreciación de los efectos cosificadores como productos de un proceso de modernización selectivo. No habría algo así como la postulación o el presupuesto de algo inherente a la modernización de las sociedades que genere procesos inevitablemente

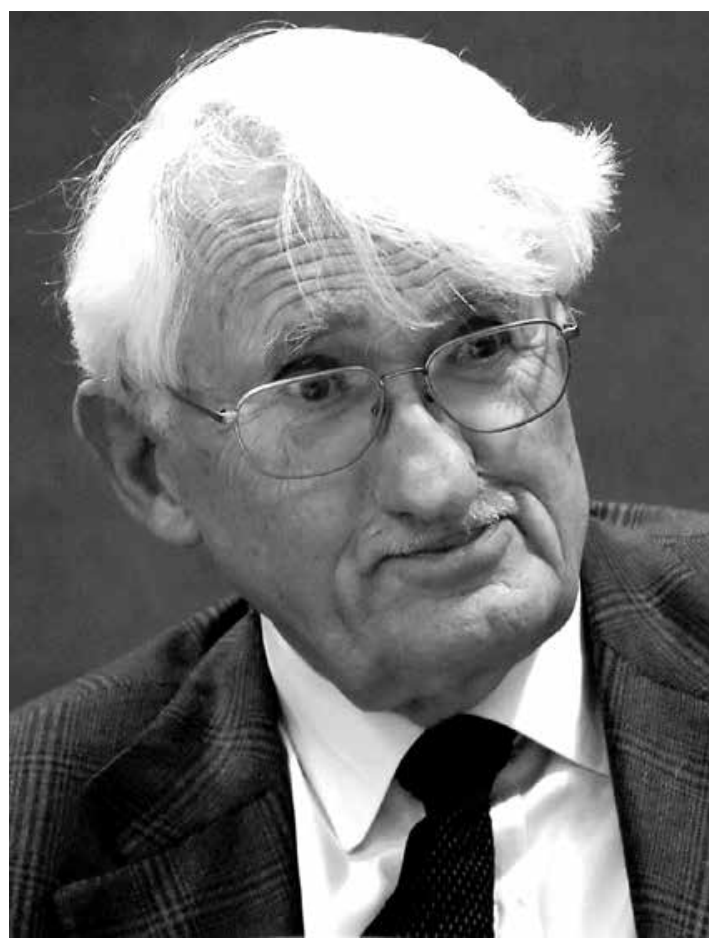

Jürgen Habermas

lesivos, sino un específico modo de realizarse históricamente - esa modernización- que, sin dudas, ha conllevado daños pero nos ha conducido más bien a efectos paradójicos, no unilateralmente perniciosos.

En términos habermasianos, el proceso de racionalización del mundo de la vida supone, en principio, una mayor diferenciación estructural entre los aspectos ligados a los individuos, las normas sociales y la reproducción cultural. Aquí podríamos fijar la ruptura y reconfiguración del marco institucional y el ejercicio del dominio propio de las formaciones sociales premodernas. Al mismo tiempo, se van gestando nuevos ámbitos sociales encargados específicamente de la reproducción material y la administración del poder, desprendidos de la vida social más cotidiana. Se trata de que el mercado y el Estado, en su forma moderna, van consolidando una organización interna específica, con reglas y atributos de carácter formal y técnico que se desligan de ciertas normativas, preceptos y comprensiones propias 


\section{La mediatización del mundo de la} vida: las relaciones humanas fundadas

en el lenguaje y la normatividad en sus distintos niveles se van 'exonerando' de la problemática del mantenimiento material de la sociedad y de la organización administrativa del poder.

de la experiencia mundano-vital. Comienzan a constituirse como subsistemas en continua complejización interna y autonomización de los mundos de la vida, a la vez que se autorregulan a través de sus específicos mecanismos o también llamamos medios de control el poder y el dinero.

Se produce lo que podríamos ahora denominar la mediatización del mundo de la vida: las relaciones humanas fundadas en el lenguaje y la normatividad en sus distintos niveles ${ }^{4}$ se van 'exonerando' de la problemática del mantenimiento material de la sociedad y de la organización administrativa del poder (asuntos a los que están abocados ambos subsistemas). Esto es lo que llamaríamos la conformación del mercado y la burocracia que, hasta cierto punto, para Habermas, suponen un componente normal de la modernización y no significan, per se,

4 El mundo de la vida se estructura, por excelencia, lingüística y normativamente. En condiciones normales, cada acción adquiere un sentido en términos de los valores y el lenguaje como un todo le proporcionan. Señalemos aquí que Habermas retoma el concepto de mundo de la vida de la tradición filosófica fenomenológica. En la TAC se dedica particularmente a revisar el desarrollo que ha efectuado Alfred Schütz sobre esta noción, aunque ciertamente luego le otorga un desarrollo propio (1987b, pp. 169 y ss.). una deformación en las bases sociales. De hecho, representan una ventaja, porque cuanto más especializados y autorregulados se constituyen esas esferas del poder político y el mercado, actuarán con mayor eficacia para su propio mantenimiento, en tanto que el mundo de la vida, en su versión moderna y racionalizada, el hecho de liberarse de esas ocupaciones, supone una potenciación de las relaciones fundadas en una racionalidad comunicativa. Es decir, las interacciones se regularán más a través del intercambio de argumentos y justificaciones que en una orden ético meramente impuesto. En última instancia, tales reglas estarán asentadas en una moral universalista posconvencional que no acepta como válida ningún tipo de imposición arbitraria (impartida por la tradición, las costumbres, la fuerza o la amenaza abierta o encubierta, los imperativos de eficiencia económica o política, etc.) $)^{5}$.

Ahora bien, considerando que estos subsistemas operan con una dinámica de expansión e intensificación sobre su entorno - pues todo lo que 'circunda' al sistema será considerado un 'entorno' en el lenguaje sistémico-funcional de Parsons y Niklas Luhmann que Habermas no tiene problemas en adoptar-, la colonización del mundo de la vida se produce porque tanto el mercado como el poder del Estado tienden a intervenir sobre ese mundo de la vida ya racionalizado en términos comunicativos. Se trata de una 'colonización' porque supone que la lógica

5 Para comprender mejor este pasaje, es imprescindible estar al tanto de su concepción de la racionalidad comunicativa que Habermas desarrolla con más detalle en el tomo I de la TAC. Aquí solo podemos hacer la alusión a la racionalidad como la capacidad para desarrollar argumentos y justificaciones con distintas pretensiones de validez y formar parte de un diálogo en este sentido. Tal capacidad se libera o potencia a la par que se debilitan las tradiciones y hábitos culturales arraigados (1987a). 
sistémica se introduce en el mundo de la vida, tratando de ajustar las interacciones, en principio articuladas a través del lenguaje, a la lógica sistémica. Los imperativos del sistema, es decir, la búsqueda de la eficiencia económica (mercado) y organizativa (estado), penetran y se imponen en los procesos de socialización, de conformación de normas sociales y transmisión cultural, de modo que ponen en peligro la propia reproducción social (1987b, p. 502).

Cabe advertir, además, que justamente esa racionalización de base del mundo social - de índole 'comunicativa' - vuelve más permeable al mundo de la vida a la influencia dañina de los subsistemas, en tanto supone formas de vida tradicionales debilitadas, un sistema normativo más abstracto y menos substancial, procesos de individuación altamente desgajados de mandatos culturales, la conformación de una excluyente o elitista cultura de expertos o especialistas (en el mundo del arte y de la ciencia). En ese sentido, la reificación no supondría necesariamente una falsa conciencia - al menos en el modo convencional como engaño o ilusión-, sino una conciencia fragmentada, empobrecida culturalmente, sin 'respaldo' cultural consolidado y con una capacidad de integración francamente debilitada que lo convierte en fácil presa de esas relaciones instrumentalizadas desde la lógica de una regulación impersonal (1987b, p. 501).

\section{La teoría del trabajo-valor y su relación con la TAC}

Llegados a este punto, parecería que tomáramos mayor distancia del marxismo, en general, y de su teoría del valor, en particular. Pero es precisamente en el caso de la colonización del mundo de la vida por parte de los sistemas que Habermas entabla una apropiación más en detalle con Marx.

Así pues, Habermas plantea, primero, una mediatización y desacoplamiento entre sistemas y mundo de la vida, estableciendo el intercambio a través de los medios que imputan la propia dinámica sistémica: el dinero, en tanto medio especifico que produce el proceso de monetarización de la fuerza de trabajo, mientras que la burocratización estatal es generada por el medio regulativo llamado poder. Vale aclarar que la monetarización no significa la mera interposición del dinero entre los interactuantes, sino la estructuración de la relación como tal y la configuración de los roles de quienes integran este tipo de vinculación, por fuera de las reglas y normas específicas del mundo de la vida. Esto es, se trata de figuras formales y abstractas conformadas en virtud del funcionamiento sistémico, aunque se terminan imponiendo en el mundo de la vida.
En ese sentido, se constituyen los papeles del individuo como 'trabajador' productor de mercancías y como "consumidor" de bienes y servicios. Si recuperamos la perspectiva dualista en torno no solo al contenido sino al procedimiento metodológico, según las palabras de Habermas, debemos admitir que, entonces, desde el punto de vista del subsistema económico, el mundo de la vida deviene como recursos para la producción de mercancías y demandas para la venta de esos bienes y servicios producidos. La conservación del propio sistema depende de su expansión e intensificación, de modo que su anclaje en el mundo de la vida y el incremento en su colonización serán vitales para su propia reproducción (1987b, pp. 262-263).

Hasta allí, Habermas expone el funcionalismo de Parsons en compatibilidad con una perspectiva marxista. El capital debe reproducirse a sí mismo expandiéndose. Se trata de una manera de entender la producción de bienes y a la vez la resolución más eficaz de las necesidades materiales.

Aunque, frente a ello, Habermas va a defender un enfoque dual a fin de no reducir la totalidad del mundo social a un punto de 
vista sistémico. Eso significa, en este contexto, que se debe entroncar la descripción sistémica con la perspectiva de la acción social. De esa manera, desde el mundo de la vida, los subsistemas operan sobre ellos como algo externo y superior - basta con imaginar una persona corriente, desde su conciencia fragmentada, enfrentando al sistema económico como un modo de organización imponentemente complejo-. Desde la apreciación de los propios agentes inmersos siempre en un mundo de la vida, la intervención del sistema significa una injerencia externa coactiva - en cierto grado- que demanda "fuerza de trabajo" a cambio de un salario.

Pues bien, aquí ya comenzamos con la traducción a la terminología marxista. Así lo hace el propio Habermas. Pero, el principal punto a favor para establecer dicha traducción es que la teoría del trabajo-valor en Marx también sostiene una perspectiva dual que permite aprehender a la vez el funcionamiento sistémico del capital y el fenómeno de la explotación laboral (1987b, pp. 476-477).

Como Habermas mismo nos recuerda, el dualismo de Marx ya está presente en el análisis de la forma mercancía en su doble condición de abstracta y concreta:

Con el análisis del doble carácter de la mercancía obtiene Marx supuestos fundamentales de teoría del valor que le permiten describir el proceso de despliegue de las sociedades capitalistas, desde la perspectiva económica del observador, como un proceso de (autovalorización o) autorrealización del capital, sometido a crisis cíclicas; y simultáneamente, desde la perspectiva histórica de los afectados (o del participante virtual), como una interacción entre clases sociales preñadas de conflictos (Habermas, 1987b, p. 473).

Ahora bien, el principal elemento transformado en mercancía, en el marco de una economía capitalista, es el trabajo que se verá naturalmente estructurado en esa misma dualidad.

En efecto, por un lado, el trabajo va a determinarse como concreto, singular, sometido a las reglas, valoraciones, normas y significaciones propias del mundo de la vida. Es decir, va a ser considerado desde el punto de vista mundano de los agentes. En paralelo con la noción de mercancía en general, se tratará aquí de estimar su específico valor de uso. Por otro lado, será considerado como fuerza de trabajo, o sea, como mercancía abstracta que adquiere valor en el mercado: su rendimiento puede ser medido y cuantificado en términos monetarios, plasmado en un salario; va conformando el componente variable del capital e integrado a su composición, se transforma en un pieza más del gran engranaje anónimo que se va reproduciendo a sí mismo y solo puede ser aprehendido en sus estructuras fundamentales desde el punto de vista contraintuitivo de los especialistas (como observadores externos). El trabajo, en su calidad de abstracto, es el elemento fundamental que se engarza bajo un mecanismo de integración a través de sus consecuencias no intencionales; deviene como abstracto en tanto que se enlaza a partir de sus efectos, que sobrepasan y son independientes de los propósitos individuales (los fines configuradores del trabajo en su aspecto concreto). Tal lógica de funcionamiento es anónima, impersonal; no está regulada por ninguna persona en especial, no está regida por ningún atributo personificado en particular, sino por el propio mecanismo de reproducir y revalorizar el capital expresado -en lenguaje sistémicocomo los imperativos de mantenimiento y expansión del sistema ${ }^{6}$.

6 Este aspecto lo retomamos de un trabajo anterior abocado a resaltar la centralidad de la noción de trabajo en la Teoría de la acción comunicativa de Habermas y su relación con la concepción dual la crítica a la economía política que lleva adelante el propio Marx (Fraiman, 2019). 
Asimismo, el trabajo se distingue de otro tipo de mercancías en cuanto es considerado fuerza viva, a la vez que mercancía abstracta. $\mathrm{Al}$ respecto, nos parece importante esta observación de Habermas: "que es una fuerza viva que 1) no surge con la finalidad de ser vendida, 2) que no puede separarse de sus propietarios y 3 ) que sólo puede ser puesta en movimiento por sus propietarios" (Habermas, 1987b, p. 474).

El trabajo vivo no desaparece al transformarse en abstracción; persiste como el contrapunto del funcionamiento anónimo del mercado. Una vez que se señala el carácter inherente del trabajo al sujeto productor, se puede aventurar una traslación contemporánea del célebre análisis de Marx en relación al fetichismo de la mercancía y su secreto (Marx, 2008, pp. 87-102). En la descripción de Marx, partimos de seres individuales, formalmente libres que producen, de manera privada, mercancías, y luego las intercambian en el mercado - en la forma más elemental de división social del trabajo capitalista que, naturalmente, luego se complejiza-; mas el valor de su producción está determinado por ese proceso de intercambio y, por lo tanto, su fuerza de trabajo será cotizada según el devenir de esas leyes, digamos, anónimas. El mercado y las mercancías que la componen ganan en autonomía frente a los propios trabajadores; las cosas inanimadas adquieren, por así decirlo, 'vida propia' regulando y determinando a los productores, quienes realmente se ocupan de crear valor y hacer posible la reproducción del sistema como tal, pero bajo el régimen fetichista esto último se eclipsa.

En términos habermasianos, el mercado o subsistema económico se transforma en una "abstracción real" (Habermas, 1987b, p. 475) que vive de los recursos succionados al mundo de la vida; lo considera como fuente de recursos disponibles y explotables, a la vez que guarda una relación de indiferencia en cuanto a las características peculiares (las significaciones singulares y rasgos concretos que se dañan) de esa esfera vital; así gana
El problema de la reificación implica un esencial intercambio desigual entre trabajo y capital para generar plusvalía. Pero hasta allí solo se trata de trabajo abstracto, monetarizado, que no se recompensa de manera suficiente con un salario justo.

-el sistema - autosuficiencia, se intensifica y expande obrando destructivamente sobre esa fuerza de trabajo que justamente lo hace posible.

Por consiguiente, el carácter dual del trabajo resulta fundamental para dar cuenta de esa metamorfosis como un proceso doloroso y reificante, desde el punto de vista del mundo de la vida y una teoría de la acción social. De ahí que el análisis de la transformación económica del capitalismo moderno solo en términos funcionalistas pierda de vista su 'dolorosa verdad', que a su vez constituye el fundamento de ese mecanismo: el trabajo vivo como creador de valor (Habermas 1987b, p. 479). Sin trabajo vivo, inserto en mundos de la vida histórica, lingüística, normativa y simbólicamente constituidos, no hay funcionamiento posible del orden capitalista.

El problema de la reificación implica un esencial intercambio desigual entre trabajo y capital para generar plusvalía. Pero hasta allí solo se trata de trabajo abstracto, monetarizado, que no se recompensa de manera suficiente con un salario justo. No obstante, el hecho mismo de monetarizar el trabajo, configurarlo en términos salariales, hace que el individuo se transforme en un 'trabajador' e ingrese al mercado en su rol de 'productor privado' formalmente libre (o independiente, pues, en principio, no depende de ningún otro ser en particular) como condición de posibilidad de hacer cotizar su fuerza de trabajo $y$, 
así, poder procurarse su supervivencia. Los demás individuos se la aparecen como otros seres independientes con los cuales no tiene una relación directa, sino mediada a través del intercambio de mercancías reguladas por las leyes del mercado. Por lo tanto, esa conciencia reificada implica una autopercepción de sí, en tanto que ser 'libre' de cualquier dependencia personal, pero al mismo tiempo 'desgajado' del mundo social circundante; se trata de un aspecto constitutivo para dar funcionamiento a toda la maquinaria. Por último, ver mutilada su libertad como autodeterminación y realización de una vida lograda. Pues no otra cosa podemos interpretar en la colonización del mundo de la vida como conciencia fragmentada que intenta compensarse monetaria y terapéuticamente por el Estado social, pero ello, a su vez, contiene otros efectos patológicos colaterales (Habermas, 1987b, pp. 490-515).

Por supuesto, el propio Habermas considera que Marx tematizó fundamentalmente el caso especial de la subsunción del mundo de la vida por la esfera económica. Debe ser complementado por el análisis de los efectos y características en el intercambio de la administración estatal (1987b, p. 483). Aun así, podríamos decir que Marx apunta a lo central, a la esfera económica capitalista y a los conflictos que se generan, sin lo cual no se puede explicar el propio rol del Estado en su regulación de la economía, legitimación política y compensación monetaria, etc. La hipótesis del Estado social intervencionista en la TAC no conmueve tales cimientos teóricos. Por el contrario, los confirma si se piensa en su rol como pacificador de clases y como compensador monetarios de las crisis sistémicas del capital ${ }^{7}$ y de las necesidades materiales y terapéuticas de los trabajadores. A su vez, el hecho de constatar los límites del Estado social en su capacidad reconciliadora entre capital y trabajo, y que su paulatino repliegue esté asociado a la revitalización de los conflictos de clases, reafirma la centralidad de la teoría marxista del valor derivado del trabajo.

\section{Principales limitaciones del planteo marxista desde el punto de vista de la TAC}

Si bien la mayor parte del presente artículo está dedicado a destacar la vinculación pocas veces reconocida y comprendida que Habermas hace de Marx, no podemos dejar de señalar algunas objeciones que también realiza a la versión marxista de la sociedad. En particular, Habermas desestima la influencia persistente de la noción de totalidad dialéctica hegeliana en el análisis marxista de la sociedad. Así, el mencionado dualismo del trabajo, de la mercancía en general y del mundo social, solo puede entenderse como una situación transitoria que está destinada a finalizar en una nueva unidad reconciliada (1987b, p. 479).

A partir de esta visión, 'unificadora', en última instancia, los procesos de diferenciación modernos son vistos siempre como 'desgarros' en la totalidad social. Entonces, Marx pasa por alto el valor intrínseco de la conformación de los subsistemas regidos por medios que fuerzan a destruir las relaciones premodernas y proponen un tipo de integración e institucionalización que en sí mismo no son dañinos, a juicio de Habermas (1987b, p. 480).

7 Vale aclarar que el Estado social, bajo los términos cómo los presenta Habermas, supone no solo la lógica de la valoración del capital a través de la producción de la plusvalía, sino también los procesos de crisis cíclica. Por caso, le ley de la baja tendencial de la tasa de ganancia forma parte de la deducciones centrales de la teoría del valor en Marx (Carcanholo, 2013). Ahora bien, Habermas no saca las mismas consecuencias que Marx al respecto. Sobre ello haremos referencia al finalizar el artículo. 
Al mismo tiempo, Marx no dispone de un concepto de racionalización más diversificado que evite la reducción de los procesos de diferenciación en el mundo de la vida como cosificación. Por el contrario, desde autores como Durkheim o Mead (Habermas, 1990), en el marco de un planteo abiertamente comunicativo, es posible delimitar analíticamente una individuación lograda de una alienación psíquica o situación social anómica ${ }^{8}$. Aquí se permite leer diferenciadamente un caso de disenso identitario - que no parte directamente de una posición de clase social- de una anomalía patológica. De modo que los procesos lesivos y los conflictos no son necesariamente derivados - de manera directa - de la situación de trabajo o el lugar en el aparato productivo - por ejemplo, las luchas por la identidad étnica, género, el control del Estado, etc.- (Leyva, 2017), aunque Habermas no niega que la dinámica del enfrentamiento entre trabajo asalariado

8 Aquí se podría aclarar que el propio Marx es al menos ambivalente sobre la cuestión en tanto admite que el individuo es producto de las interacciones sociales, sin embargo, no saca ninguna conclusión con respecto a los medios que posibilitan las individuación en cuanto a su potencial emancipatorio. Pues solo asocia esa individuación a un proceso de alienación en el cual todos los elementos que intervienen allí, operan al servicio de la dominación. Probablemente, la influencia de Hegel esté presente en esa concepción interactiva del individuo - incluso para criticar de pasada a Fichte (Marx, 2008, p. 58) - , pero un Hegel que termina interpretando las individuaciones como "desgarros" orientados a una reconciliación final. Al respecto, Habermas (1986) ha resaltado las diferencias entre los escritos de Jena de Hegel y la posterior elaboración de la Fenomenología del Espíritu en donde la constitución intersubjetiva de la individualidad termina subsumida en una totalidad unificadora.
Habermas desestima

la influencia persistente de la noción de totalidad dialéctica hegeliana en el análisis marxista de la sociedad. Así, el mencionado dualismo del trabajo, de la mercancía en general y del mundo social, solo puede entenderse como una situación transitoria que está destinada a finalizar en una nueva unidad reconciliada.

y capital continúa ocupando un lugar central (1987b, p. 483).

En última instancia, Habermas también imputa a Marx, pese a poseer un concepto de sociedad articulado en dos niveles, persistir en un reduccionismo de fondo en torno a la teoría de la acción social bajo el modelo de la actividad teleológica y de la racionalidad con arreglo a fines, que ubica la formación de los procesos de reificación

por debajo del nivel de interacción y a tratar la deformación de las relaciones interactivas, es decir, lo mismo la desmundanización de la acción comunicativa, adaptada ahora a medios de control, que la tecnificación del mundo de la vida a que ello da lugar, como si fueran fenómenos derivados (1987b, p. 484).

En ese sentido, Marx compartiría tales presupuestos de una teoría social con Max Weber y eso constituye un elemento determinante en los intentos posteriores - en el llamado marxismo occidental- de articular la crítica a la economía política de Marx con la crítica a la dominación burocrática en Weber. 


\section{Breve alusión a algunas críticas a Habermas}

Tampoco es posible obviar completamente las principales objeciones que recibe la TAC de Habermas, que en gran parte pueden considerarse de inspiración marxista.

Entre las críticas más importantes podemos mencionar que el desdoblamiento de la sociedad en el plano sistémico por un lado y, por el otro, simbólico-normativo o mundo, conlleva una serie de ficciones erróneas. Según Axel Honneth (2009), se trata de una trasposición especulativa sin mediaciones, efectuada a partir de la división dual de la acción social en estratégica y comunicativa, que da como resultado una separación ilusoria entre un ámbito sistémico, depurado de normatividad y de lenguaje, donde el poder es leído como un medio de control necesariamente desubjetivado y, del otro lado de la frontera, el mundo de la vida como esfera purificada de poder o que, en todo caso, lo experimenta como algo externo ${ }^{8}$. A la par, la perspectiva de Habermas, imbuida en exceso por la lectura sistémico-funcional de las relaciones de poder y del proceso de producción económica (Mc Carthy, 1992), conduciría finalmente a ontologizar e inmunizar los propios sistemas como tales (García-Granero y Ortega Esquembre, 2019), pues constituye, en sí mismo, un paso evolutivo positivo. Cualquier proceso de 'desdiferenciación' constituiría un retroceso, un movimiento reactivo. Por lo tanto, permanece el interrogante acerca de si una comprensión sistémico-funcional del mercado y del Estado no conduciría a interpretarlos como la culminación de un proceso evolutivo de la humanidad y, de esa manera, dejan de ser considerados productos humanos situados histórica y socialmente, susceptibles de ser transformados, incluso de manera radical, tal como lo sostendría una postura marxista?.

\section{Últimas palabras a modo de conclusión provisoria}

Por cierto, como decíamos al inicio del escrito, un intento de articulación no significa hacer forzosamente coincidir o complementar dos teorías, ignorando sus disonancias.

En consecuencia, la tarea no aparece exenta de dificultades y paradojas. Por caso, si tenemos en cuenta que entre las deducciones más importantes que desarrolló Marx en El Capital, derivadas en particular de su teoría del trabajovalor, se encuentra la ley de la tendencia hacia la baja de la tasa de ganancia (Carcanholo, 2013). Aunque se trate de una tendencia a largo plazo no libre de contratendencias y situaciones coyunturales que pueden neutralizar

8 Se ha desarrollado una amplia literatura crítica con respecto a este tópico habermasiano. Se puede consultar Hans Joas (1991) y en el ámbito hispanoparlante, Romero Cuevas (2011). parcialmente esa condición, muchas de ellas ya consideradas por el propio Marx (2009, p. 297 y ss.). Aun así, estamos aquí en una cuestión particularmente áspera, porque tal ley explicaría el carácter intrínsecamente contradictorio del sistema capitalista y colisionaría con la lectura sistémica que ofrece Habermas. Sin embargo, las crisis sistémicas son un aspecto que Habermas no solo no ignora, sino que tiene fundamentalmente en cuenta para explicar el imprescindible rol regulador de la economía capitalista cumplido por el Estado social. Con todo, habría que pensar cuáles son los límites de una regulación aun exitosa, y cómo puede

9 Aquí se podría conectar con Habermas, la concepción fundamentalmente histórica que presenta Marx que elude una ontologización del sistema capitalista (Musto, 2015 y Pérez Cortés, 2017). 
justificar que el mercado, como institución social, no se desdiferencie y no se derrumbe por su propia dinámica interna - y si eso mismo constituye también un progreso y no un mero cambio reactivo.

Al mismo tiempo, habría que reflexionar hasta qué punto la crítica marxista de la economía política no presupone una visión comunicativa fundada en el entendimiento mutuo -que es dañada sistemáticamente por la lógica del capital-, y si no admite la existencia de una infraestructura racional comunicativa en cuanto capacidad subjetiva -o intersubjetiva - para contrarrestar la lógica de la valorización del capital y construir acuerdos orientados al interés general.

En suma, tal puesta en relación debe presentar dos direcciones recíprocas de reflexión: pensar los alcances y las problemáticas de cada perspectiva a partir del cotejo entre sí. A la vez, desarmar falsos dilemas que, a nuestro entender, constituyen un verdadero obstáculo epistemológico para intentar llevar a cabo un cruce fructífero.

En otras palabras, esta articulación me parece sumamente necesaria como aporte a la construcción de la teoría social en términos más globales, que es sensible a la estructuración lingüística de la realidad social, a la constitución de una subjetividad descentrada y al ejercicio de una crítica intramundana que es capaz de dar cuenta de todos esos aspectos, pero que a la vez no significa tomar la teoría del valor, los conflictos productos de la economía y los antagonismos de clases como trasfondo prescindibles.

\section{Referencias}

Carcanholo, R. A. (2013). La ley de la baja tendencial de la tasa de ganancia. Filosofía, Política y Economía en el Laberinto, 38, 27-41.

Fraiman, J. A. (2019). La relevancia del trabajo en la Teoría de la acción comunicativa de Jürgen Habermas. Revista Trabajo y Sociedad, 33(20), 59-81.

García-Granero, M. y Ortega Esquembre, C. (2019). ¿Teoría crítica o inmunización del sistema? Acerca de la dicotomía habermasiana entre sistema y mundo de la vida. Tópicos Revista de Filosofía, 56, 311-337.

Guiddens, A. et al. (1991). Habermas y la modernidad. Madrid: Cátedra.

Habermas, J. (1986). “Trabajo e Interacción. Notas sobre la Filosofía hegeliana del período de Jena", en Habermas, J. Ciencia y Técnica como Ideología (pp. 11-51). Madrid: Tecnos.

Habermas, J. (1987a). Teoría de la Acción Comunicativa. Tomo I. Racionalidad de la acción y racionaización social. Crítica de la razón funcionalista. Madrid: Taurus.
Habermas, J. (1987b). Teoría de la Acción Comunicativa. Tomo II. Crítica de la razón funcionalista. Madrid: Taurus.

Habermas, J. (1988). "La crisis del Estado de Bienestar y el agotamiento de las energías utópicas", en Habermas, J. Ensayos políticos (pp. 113-134). Barcelona: Península.

Habermas, J. (1989a). "Observaciones sobre el concepto de acción comunicativa (1982)", en Teoría de la Acción Comunicativa (pp. 479-507). Complementos y estudios previos. Madrid: Cátedra.

Habermas, J. (1989b). El discurso filosófico de la modernidad (doce lecciones), Madrid: Taurus.

Habermas, J. (1990). "Individuación por vía de la socialización. Sobre la teoría de la subjetividad de George Herbert Mead", en Habermas, J. Pensamiento postmetafísico. Madrid: Taurus.

Honneth, A. (2009). Crítica del Poder. Fases en la reflexión de una Teoría Crítica de la sociedad. Madrid: Editorial Antonio Machado. 
Joas, H. (1991). “The Unhappy Marriage of Hermeneutics and Functionalism", en Honneth, A y Joas, H., Communicative Action. Essays on Jürgen Habermas's The Theory of Communicative Action. Cambridge, Massachusetts: The MIT Press.

Leyva G. (2017). "El concepto de 'crítica' en $E l$ Capital de Karl Marx. Dimensiones, presuposiciones, problemas" en Aroch, Paulina et al. (coord.), Das Kapital. Marx, actualidad $y$ crítica (pp. 36-54). México: Siglo XXI.

Marx, K. (2008). El Capital. El proceso de producción del capital. Libro I. Tomo I. (trad. de Pedro Scarón). Madrid: Siglo XXI Editores.

Marx, K. (2009). El Capital. El proceso global de la producción capitalista. Tomo III. Libro III. (trad. de Pedro Scarón). Madrid: Siglo XXI Editores.

Mc Carthy, T. (1992). "Complejidad y democracia: las seducciones de la teoría de los sistemas", en Ideales e Ilusiones.
Reconstrucción y deconstrucción en la teoría crítica contemporánea (pp. 165-192). Madrid: Tecnos.

Musto, M. (2015). “Introducción”, en Musto, M. (editor) De regreso a Marx. Nuevas lecturas y vigencia en el mundo actual (pp. 7-40). Buenos Aires: Editorial Octubre.

Pérez Cortés, S. (2017). "Notas acerca del concepto de 'crítica' en El Capital", en Aroch, Paulina et al. (coord.), Das Kapital. Marx, actualidad y crítica (pp. 19-35). México: Siglo XXI.

Romero Cuevas, J. M. (2011). Entre hermenéutica y teoría de los sistemas. Una discusión epistemológico-política con la teoría social de J. Habermas. Isegoría. Revista de Filosofía Moral y Política, 44, 139-159

Sitton, J. (2006). Habermas y la sociedad contemporánea. México: Fondo de Cultura Económica. 